Gilberto Owen publica en 1934 sus traducciones de ocho poemas de Emily Dickinson para un público lector hispanohablante que apenas la conoce. Al hacerlo, el mexicano pone de manifiesto una afinidad con la poeta no sólo en términos de temperamento sino también, en el ámbito de la escritura, en términos de temas, tratamientos, intereses y figuraciones poéticas. El presente artículo sostiene que la labor de traducción que realiza un poeta como Owen, además de procurar la difusión e integración de autores extranjeros en el canon de poesía nacional, es relevante en tanto tiene una incidencia considerable en su propia producción lírica.

PALABRAS CLAVE: traducción, poesía, influencia, adaptación, Emily Dickinson, Gilberto Owen.

\title{
«La medida exacta de su luz»: Emily Dickinson y las «versiones a ojo» de Gilberto Owen
}

Juan Carlos Calvillo R.

Centro de Estudios Lingüisticos y Literarios El Colegio de México
"The "vital Light": Emily Dickinson and Gilberto Owen's "Rough versions"»

In 1934 Gilberto Owen publishes his translations of eight poems by Emily Dickinson for the benefit of a Spanish-speaking readership that barely knows her. In doing so, the Mexican poet acknowledges a particular affinity with her in terms not only of character but also of poetic themes, procedures, interests, and conceptions. This article claims that the translation work undertaken by a poet such as Owen, apart from its endeavor to expand the reaches of and to integrate foreign authors to the national canon, is significant because of the impact it has in his own poetic production.

KEY WORDS: translation, poetry, influence, adaptation, Emily Dickinson, Gilberto Owen. 


\section{ANTECEDENTES}

El 29 de abril de 1934, en las páginas centrales 238 del suplemento cultural del diario El Tiempo de Bogotá, aparecen las llamadas «Versiones a ojo» de ocho poemas de Emily Dickinson que realizara en años previos, presuntamente durante su estancia diplomática en Nueva York (1928-1929), el poeta mexicano Gilberto Owen. Para estas fechas son pocos los lectores hispanohablantes que conocen el nombre de Emily Dickinson, que saben algo al respecto de su existencia ermitaña y grafomaníaca, y menos aun los que han podido leer fragmentos de su obra, ya sea en lengua inglesa o en traducción al español. Dickinson vivió toda su vida adulta recluida en la finca de su padre, en el pequeño pueblo de Amherst, Massachusetts - si bien por voluntad propia, como una declaración personal de libertad e independencia-, y no fue sino hasta I89o, cuatro años después de su muerte, que una primera selección de sus poemas trascendió el círculo privado de familiares y amigos. En el año de r 934 en que Gilberto Owen publica sus «versiones», sólo un lector que estuviera en íntimo contacto con la literatura norteamericana tendría noticia de que Conrad Aiken la había situado ya «among the finest poets in the language» (citado en Mitchell y Stuart 2009: 235), sentando así el precedente necesario para la instauración de la tradición crítica que hoy en día reconoce en Emily Dickinson a «certainly America's greatest woman author and possibly its greatest poet of either gender» (Griffin Wolff, citada en Thomason 200I: I4I).

Con todo, no deja de ser probable que Emily Dickinson sea, incluso hasta la fecha, la figura más excéntrica en el panorama literario de los Estados Unidos. Desde la privacidad de su alcoba en el segundo piso de una casa provinciana, una mujer soltera, retraída y prácticamente desconocida para el mundo habría de crear un

cuerpo de poesía tan original, tan extraordinaria e inaudita que, al día de hoy, ciento treinta años después de su descubrimiento, sigue pareciendo difícil explicarla como un producto de su propia época. La posteridad la recuerda con ternura como «the Belle of Amherst» y su vida es ya tan legendaria como su obra; sin embargo, en su tiempo no hubo casi nadie que la conociera, por no decir ya alguien que pudiera entenderla. No obstante, esta figura ha quedado encumbrada en el canon literario de los Estados Unidos quizá precisamente por la asombrosa originalidad de su poesía. La crítica reciente ha llegado a distanciarla de las tradiciones del romanticismo europeo y el puritanismo colonial de las que abreva para colocarla entre las obras que anticipan las vanguardias o, incluso, dada su vigencia ideológica, entre las que las suceden. La interminable especulación que ha suscitado su famoso encierro, la privacidad de su vida y las relaciones que estos entablan con el hermetismo de su escritura - sencilla sólo en apariencia, pero en verdad críptica y poderosa - han hecho de Emily Dickinson uno de los descubrimientos más notables de los siglos xx y xxi.

La influencia constante, insoslayable, de la poesía de Emily Dickinson, con su uso creativo del lenguaje, la extravagancia de su versificación y el poderoso efecto de su pensamiento excepcional, tuvo un impacto determinante en el curso que siguió la poesía estadounidense y, directa o indirectamente, en el desarrollo de la poesía moderna y contemporánea. No es de sorprender, pues, que su obra se haya traducido a más de veinte idiomas en todo el mundo, entre los que destacan versiones célebres en francés, alemán, ruso, polaco y danés, así como otras traducciones, menos conocidas en Occidente, al persa, chino, japonés y coreano. ${ }^{\mathrm{I}} \mathrm{A}$ la lengua

I Una edición especial de The Emily Dickinson Journal 
española su poesía se ha vertido también en numerosas ocasiones: no son menos de cuarenta los traductores de habla hispana que he podido documentar a lo largo de una investigación exhaustiva, todos los cuales, dependiendo de su contexto cultural y literario, su voluntad interpretativa y sus ambiciones poéticas, han producido versiones considerablemente distintas del corpus dickinsoniano; distintas, reitero, en vista sobre todo de que la prosodia y la musicalidad, las anomalías gramaticales, la indeterminación semántica y la misteriosa fuerza características de la poesía hermética de Dickinson son aspectos que obligan al traductor a interpretar de manera ineludible.

La historia de la traducción española de Emily Dickinson es tema de un estudio aparte (que se encuentra ya en preparación y que habrá de publicarse en fechas próximas), pero baste, para efectos de este trabajo, con señalar los hitos en su breve devenir. Según se tiene noticia, el primero en traducir versos de «the Belle of Amherst» a nuestra lengua fue Juan Ramón Jiménez, que incluyó tres poemas del volumen The Single Hound en su Diario de un poeta recién casado (I9I6). ${ }^{2}$ Dieciocho años más tarde es que aparecen, en Colombia, las ocho «versiones a ojo» del mexicano Gilberto Owen, que, según se afirma en la nota que las acompaña, son sólo parte de una selección de doscientos poemas traducidos, inéditos al día de hoy. No obstante, el primer volumen significativo de la obra poé-

estuvo dedicada a dar cuenta del trabajo y los problemas que implica la traducción de una poética tan exigente a una variedad de lenguas y culturas en todo el mundo: «Swearing by the Cuckoo: Translators on Translating Emily Dickinson's Poetry.» The Emily Dickinson Journal Vol. 6, No. 2, otoño de 1997 .

2 Los poemas son: II «The Soul that has a Guest» («El alma que tiene Huésped»), xxvII «The gleam of an heroic act» («iResplandor de un acto heróico!») y LV «I send two Sunsets - ( («os Puestas de sol te mando») (I9I7: 243-244). tica de Dickinson que se publicó en español es el que preparó un matrimonio de poetas de la Generación del 27, Ernestina de Champourcin y Juan José Domenchina, que es particular-

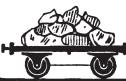
mente notorio porque incluye un prólogo en el que este último, Domenchina, denosta la "poquedad lírica» de sus «módicos pero harto personales vagidos» (I946: I8) y admite que jamás la habría traducido a nuestra lengua de no haberse «enterc[ado] mi mujer» (I946: 25). Esta Obra escogida se editó en Barcelona en I945 e inmediatamente después en la Ciudad de México. A ella le sucedieron las selecciones de Marià Manent (I957) y Silvina Ocampo (I985), que tuvieron gran circulación en el mundo hispanohablante. En fechas más recientes, casos similares en lo que respecta a difusión son las recopilaciones de Margarita Ardanaz para Cátedra (1987), Amalia Rodríguez Monroy para Alianza (200I), Manuel Villar Raso para Hiperión (200I) y Lorenzo Oliván para Pre-Textos (200I). No fue sino hasta los años de 20I2-20I3 que se publicaron tres versiones distintas de la obra completa de Dickinson en nuestra lengua, cabe señalar, todas ellas en España. ${ }^{3}$ Por lo general, y por desgracia, las traducciones que se han realizado en el continente americano no son ni publicaciones independientes (es decir que, por lo común, son puñados de poemas recogidos en revistas o en compilaciones diver$\left.\mathrm{sas}^{4}\right)$ ni tampoco selecciones representativas de

3 Se trata de las siguientes ediciones: Poesía completa, en traducción de Enrique Goicolea (Amargord, 20I2), Poesías completas, en traducción de José Luis Rey (Visor, 2013) y los tres tomos de Poemas I-6oo. Fue - culpa - del paraíso, Poemas 60I-I200. Soldar un abismo con aire y Poemas I20I-I786. Nuestro Puerto un secreto, en traducción de Ana Mañeru Méndez y María-Milagros Rivera Garretas (Sabina, 20I2, 2013 y 2015 , respectivamente).

4 En este caso se encuentran, por citar sólo algunos ejemplos, las traducciones de Agustí Bartra, catalán (Antología de la poesía norteamericana, UNAM, 1984), Ernesto Cardenal y José Coronel Urtecho, nicaragüenses (Antología de 
su obra, con contadas excepciones, como las de Anna María Leoni, venezolana (2005), Rolando Costa Picazo (20II) y Delia Pasini (20I4), argentinos. 5

\section{GILBERTO OWEN Y LAS «VERSIONES A OJO»}

Como ya mencionaba, pues, y hasta donde puede saberse con certeza, el primero en emprender la tarea de traducir a Emily Dickinson al español fue el poeta Juan Ramón Jiménez, que incluyó versiones de tres miniaturas, bajo el título de «Recuerdos de América del Este escritos en España», en el libro de rgr6 que inaugura la segunda etapa de su poética, la llamada «etapa intelectual»; un cambio que se suscita a raíz, entre otras cosas, del contacto directo que tuviera con la poesía en lengua inglesa en su viaje por los Estados Unidos con su esposa Zenobia Camprubí. «El encuentro de Juan Ramón con la nueva poesía norteamericana», del que deriva su Diario de un poeta recién casado, es, en palabras de Soledad González Ródenas,

tan singular que reconoce en ella un avance sobre la corrección de estilo que trataba de imponerse a sí mismo... La frescura, la sencillez, la elegancia, el laconismo y la introspección y proyección espiritual de Emily Dickinson, Amy Lowell [y] Robert Frost, [...] entre otros, son para él la constatación de que sus recién estrenados parámetros estéticos tenían

la poesía norteamericana, El Perro y la Rana, 2007), Rosario Castellanos y Bernardo Ortiz de Montellano, mexicanos (El surco y la brasa, Fondo de Cultura Económica, I974).

5 Mención aparte (dado que no pretenden ser ediciones representativas) merecen, a mi juicio, los 55 poemas en traducción del mexicano Alberto Blanco (Hiperión, 2010), seguidos de la Amberst Suite, una serie de cuarenta poemas dedicados a Emily Dickinson, así como el volumen Carta al mundo: veinticinco poemas de Emily Dickinson, en versiones del también mexicano Hernán Bravo Varela (Bonobos, 20I7). una salida absolutamente válida en la poética contemporánea. (2005: 65)

Este «desarrollo natural» en la poesía de Juan Ramón, que lo exhortó, alrededor de i9i6, a distanciarse de los temas y motivos del modernismo y del simbolismo francés, y a acercarse en cambio a un tratamiento simple y claro de conceptos y emociones, nunca dejó de confesar «su plena adhesión y hermanamiento con la nueva poesía angloamericana» (González Ródenas 2005: 66); por lo contrario, lo llevó a proponer, cosa rara para aquellos tiempos, la incorporación de la obra ajena en la propia, en busca de un tono fresco, una estética más depurada, una relación rejuvenecida con la poesía. Como afirma Pedro Henríquez Ureña,

El deliquio interior perdura, y se enriquece de ideas, de problemas, de interrogaciones; [...] la visión de las cosas nunca pierde su esplendor, pero gana en simplicidad, en grandeza de líneas y pureza de colores; la música va moderando su empuje y haciéndose más sutil, hasta llegar a los ritmos intelectuales, abstractos, del verso libre; en general, el poeta se torna más severo, más fuerte, con vigor de madurez. (I9I9: 256)

Este Juan Ramón, el de las «síntesis ideales», el del «lirismo de la inteligencia», el que redescubre la poesía en Eternidades ( $i \mathrm{Oh}$ pasión de mi vida, poesía / desnuda, ${ }^{6}$ mía para siempre!», I974: I43), es el Juan Ramón Jiménez que, a decir

6 «Esta "poesía desnuda” se manifiesta en poemas breves y escuetos que parecen ser el resultado de un despojamiento expresivo en todos los niveles: léxico, sintáctico, métrico, estrófico, temático y simbólico. La simplificación extrema desemboca en exclamaciones que eternizan el instante al cristalizar impresiones fugitivas... En suma: una especie de misticismo estético en el cual la palabra transparente aparece como la revelación de la esencia de las cosas» (Stanton I998: I3I). 
de Tomás Segovia (2001: 15-16) y Guillermo Sheridan (1985: 158-160), fue una influencia decisiva en el grupo de escritores mexicanos que, bajo el nombre de «Contemporáneos» —homónimo de su revista más importante-, agrupa a una generación cuyo vínculo, más que una visión estética o una afiliación social o política en común, es la amistad que trabaran sus miembros entre los años de 1920 y 1932 en la Ciudad de México. Lectores, traductores y herederos de los modernistas europeos, determinados en la búsqueda de la "poesía pura» (Stanton 1998: I27-I28), los Contemporáneos -Jaime Torres Bodet, Jorge Cuesta, José Gorostiza, Bernardo Ortiz de Montellano, Carlos Pellicer, Salvador Novo, Xavier Villaurrutia y Gilberto Owense dieron a la tarea de «traer un hálito de aire fresco a una poesía [mexicana] casi estancada, a hacerla participar en las nuevas corrientes mundiales» (Dauster 1963: 5) o, como refiriera el propio Torres Bodet, de «establecer un contacto entre las realizaciones europeas y las promesas americanas» (citado en Dauster 1963: 8).

Junto con su amigo Xavier Villaurrutia, es Gilberto Owen, el más joven del grupo de Contemporáneos, el que más aprende de Juan Ramón Jiménez, el que más seriamente se toma la encomienda, en palabras de Henríquez Ureña, de "[apartarse] del mundo de las diarias apariencias [para que quede sólo] la esencia pura de la luz y la música del mundo» (citado en Sheridan 1985: 158). Es probablemente debido a la influencia de Juan Ramón que el joven Owen conoce la poesía de Emily Dickinson, aunque en el texto titulado "Datos biográficos», la nota o postfacio que sucede a las «Versiones a ojo» en el suplemento dominical de El Tiempo bogotano, el poeta-traductor manifiesta haber realizado un viaje a Amherst «que cuenta decididamente en nuestra vida» y que estuvo dedicado a descubrir y dibujar «amorosamente los litorales de su mundo» (1934b). (De las misiones consulares de Owen en los Estados Unidos se sabe relativamente poco; a juzgar por la relativa cercanía de Amherst y Nueva York, bien pudo haber visitado el pueblo natal e incluso la finca de Emily Dickinson, pero cabe también la posibilidad de que tal viaje sea una de las tantas invenciones de un escritor al que mucho le gustaba fabular su biografía).

Comoquiera que sea, es cierto, como bien ha hecho notar Luis Mario Schneider, que existe entre los dos una «afinidad espiritual» (citado en Beltrán 20r4: 40) que explica, por razones afectivas tanto como poéticas, por qué habría Owen de sentirse atraído por el genio y la imaginación de Dickinson. Los dos son poetas que dicen «toda la Verdad, pero sesgada» («Tell all the Truth but tell it slant - / Success in Circuit lies», I976: 506); 7 los dos son poetas que aprovechan la indeterminación del lenguaje para potenciar su capacidad expresiva, que buscan una poesía ingobernable, abierta a la coexistencia y simultaneidad de múltiples posibilidades interpretativas. Sobre todo, ambos son poetas que viven en la escritura, por ella y a través de ella: Dickinson, confinada a la «circunferencia» de su alcoba, y Owen, para quien «el constante viajar [fue] una forma de encierro» (Cohen s/f: 5), son creadores que viven una vida marcada por la privacidad y la privación; son artistas que se recluyen en su propio ser, de una u otra forma, con el objeto de convertir la poesía en el locus de una peregrinación al interior

7 Para fines de este artículo (salvo en los casos de los poemas Jir29 y J883, de los que no existe versión temprana) se utiliza la edición de Martha Dickinson Bianchi de The Collected Poems of Emily Dickinson, ya que el texto que sigue (considerablemente editado y domesticado, como es bien sabido, por Thomas Wentworth Higginson, Mabel Loomis Todd et al.) es el único que podía haberse encontrado a disposición de Juan Ramón Jiménez y Gilberto Owen. Es menester aclarar que esta edición ha sido ya consensual y sucesivamente reemplazada por los trabajos de Johnson (1955), Franklin (1998) y Miller (2016). 
de la consciencia. Por tanto, no es de extrañar que Owen haya encontrado en Dickinson a una compañera de viaje: ya en el año de 1929 el poeta le comunica en una carta a Villaurrutia que no se siente «mover[se] entre extranjeros»: «Tú lo sabes, al acostarte con la poesía de Blake ${ }^{8}$ —aunque fuera en París - y yo, que me acostaría, aquí, con la de la Dickinson» (1996: 266).

A juzgar por lo que escribe en otra carta, esta vez para Alfonso Reyes, la fascinación de Owen tiene su origen en una suerte de deferencia: "Quiero escribirle una carta muy larga sobre Emily Dickinson», le confiesa. «En diciembre es su centenario, y aquí pasará inadvertido. Yo tengo algunas traducciones y notas, que no he podido ordenar, sobre su sueño. ¿Cómo podría yo celebrarlo?» (1996: 276). Podría parecer, pues, que las ocho traducciones que Owen rescata de sus papeles neoyorkinos y publica tiempo después en Colombia tienen el propósito de «celebrar» la poesía de Dickinson, de darla a conocer en Hispanoamérica, o (como él mismo aduce en «Datos biográficos») de hacerla «resucitar [magnífica] en otro siglo» (1934b). Sin embargo, como muy pronto se adivina al leer las traducciones, hay una doble intención por parte de Owen o, por decirlo de otro modo, una asimilación de poeta y traductor. Como apunta Alfredo Rosas, cuando Owen traduce a la neoinglesa

se revela a sí mismo y, simultáneamente, revela una de las influencias más importantes en su obra, así como sus características afines con [ella]... Gilberto Owen lee, traduce y escribe sobre la poesía de Emily Dickinson porque, al hacerlo, es como si se pusiera frente a un espejo y contemplara su propio rostro. (2009: 28-29)

8 Xavier Villaurrutia tradujo El matrimonio del cielo y el infierno, de William Blake, y lo publicó en Contemporáneos en 1929.
Los ocho poemas de Emily Dickinson que publica Owen en El Tiempo de Bogotá no son, ni por mucho, el resultado de una selección aleatoria o candorosa; por lo contrario, los criterios que gobiernan la antologización de los textos, tanto como los que rigen la labor de traducción, delatan una intencionalidad harto significativa. Uno de ellos, por ejemplo, «A route of evanescence» (xv), que describe la huella que imprime el paso instantáneo de un colibrí por el espectro perceptual del ser humano, parece interesarle a Owen por el experimento poético que representa captar un fenómeno en términos de la conmoción que provoca:

Un camino desvaneciéndose

Al girar de una rueda;

$Y$ resonancias de esmeralda,

Y frenesís de grana;

Cada capullo en la espesura

Alza la cabeza vencida

Tal vez llega el correo de Túnez,

Cabalgata feliz de la mañana.

$$
(\text { I934a })^{9}
$$

De este poema, «[a] precise yet impressionistic word painting» (Leiter 44), fascina a Owen no sólo el hecho de retratar el vuelo del ave en todo su esplendor, y no sólo que en él quede plasmada, también radiante, la estupefacción de los sentidos: quizá lo que más le llama la atención es la espontaneidad del intento naturalmente humano de someter al entendimiento el suceso que acaba de acontecer ( Tal vez llega el correo de Túnez», v. 7). Tal cosa sugiere verlo a la luz de los poemas que lo acompañan. Por poner otro caso, la primera de las «Versiones

$9 \mathrm{XV}$ «A route of evanescence / With a revolving wheel; / A resonance of emerald, / A rush of cochineal; / And every blossom on the bush / Adjusts its tumbled head, - / The mail from Tunis, probably, / An easy morning's ride.» (1993: 86). 
a ojo» propone la imaginación poética como salvación única en un mundo amenazado por la carencia y la zozobra:

Una pradera se hace con un trébol

Y una abeja.

Un trébol y una abeja

Y fantasía.

También se hace sólo con fantasía

Cuando hay pocas abejas.

$$
(\mathrm{r} 934 \mathrm{a})^{\mathrm{ro}}
$$

Este breve poema es un divertimento, desde luego, pero incluso en su candor se alcanza a entrever una creencia profunda en el poder de la imaginación que construye el mundo del poeta. $\mathrm{E}$ tercero es más complejo, y en sus únicas dos estrofas se da a la tarea de afrontar la insuficiencia del lenguaje, el abismo que se interpone entre la experiencia y su representación:

Hallele forma a todo pensamiento Que me mire, menos a uno;

Y ese me burla y es por él mi boca Mano empeñada en dibujar el sol.

Ante razas nutridas de tinieblas; ¿Cómo dirías tú el tuyo propio? ¿Podrías hacer llamas del carmín O del añil hacer el mediodía?

$$
(\mathrm{I} 934 \mathrm{a})^{\mathrm{II}}
$$

Es el lenguaje, pues, y la consciencia humana que lo acompaña, lo que convierte la escena natural en un texto colmado de mensajes, un sistema semiótico donde todo es signo a la espera de su transformación en significado. Por último,

Io VCVII «To make a prairie it takes a clover / and one bee, - / One clover, and a bee, / And revery. / The revery alone will do / If bees are few.» (1993: 134).

II XXXI «I found the phrase to every thought / I ever had, but one; / And that defies me, - as a hand / Did try to chalk the sun // To races nurtured in the dark; - / How would your own begin? / Can blaze be done in cochineal, / Or noon in mazarin?» (I993: 19). el octavo es un poema oscuro, fatídico, en el que un advenimiento cotidiano se convierte en presagio; el mundo natural se vuelve temible, incluso insoportable, tan pronto se reconoce que está cargado de amenazas de muerte y decadencia:

Presentimiento es esa caída larga sombra

Cifra en el prado de que el sol se va;

Mensaje a la asustada alfombra

De que llega la oscuridad.

$$
(\mathrm{I} 934 \mathrm{a})^{\mathrm{I2}}
$$

La sombra en el jardín se convierte así en un augurio, es "Cifra», comunica una advertencia sobre la extinción de la luz que está por venir (cfr. Vendler 2006: 87). El prado se "asusta» en el poema, pero, desde luego, la anticipación, el presentimiento, sucede sólo en el territorio de la mente: es en la consciencia, un dominio exclusivamente humano, que el mundo natural se interpreta, se traduce, se vuelve significativo.

Todos ellos son temas que le resultan de particular interés a Owen en esta coyuntura en su vida: son temas, e incluso imágenes, que figuran también en los poemas que escribe precisamente durante su estancia solitaria y atormentada en los Estados Unidos, aislado entre «todas estas gentes que no son de mi raza, que apenas me entienden» (citado en Stanton 2008:74I); los poemas que aparecen más tarde en el volumen Línea (I930), como, por ejemplo, en su fundamental «Autorretrato o del subway» («Ventana a no más paisaje y sin más dimensiones que el tiempo», 1996: 65) o, por mencionar un caso distinto, en el texto que titula «Espejo vacío», del que cito sólo un fragmento:

esa sombra a la izquierda del sol es la que te desnuda

ahora es la mitad negra de tu rostro la exacta

I2 LXVII «Presentiment is that long shadow on the lawn / Indicative that suns go down; / The notice to the startled grass / That darkness is about to pass.» (I993: II8). 
tu realidad es el misterio de la palabra que nada nombra

Sufro tu voz caída poesía

se movía en árboles y se unta ahora en mudas alfombras

sabes que hay voces que nunca se muestran desdobladas.

(1996: 52)

Con todo, de las ocho "Versiones a ojo» de Emily Dickinson, ninguna resulta tan reveladora, tan oweniana, como la quinta, «Una omnipresencia de plata». Presento el original a continuación, puesto que la comparación es relevante:

An everywhere of silver,

With ropes of sand

To keep it from effacing

The track called land.

(XxII; I993: 90)

Owen lleva a cabo el trasvase, en versos eneasílabos, en un serventesio en el que sólo son consonantes los versos pares. El resultado es el siguiente:

Una omnipresencia de plata Atada con cuerdas de arena

Para que no borre el recuerdo

De lo que fue tierra morena.

(1934a)

El cotejo de original y traducción revela al instante una única alteración de importancia (más allá de la adición, por cuestiones prosódicas, de la palabra «Atada», v. 2). El sello de Owen se encuentra en la inserción de una rima espuria, la palabra «morena» (v. 4), que, desde luego, no es una decisión inocente: con este injerto, Owen transforma la típica contempla- ción dickinsoniana del paisaje en una evocación de México, la «tierra morena» que para él ya «fue» (v. 4); el México que tanto añora desde su exilio neoyorkino.

Es así que el «Mundo extraño e inesperado» de Dickinson, que desconcertaba a Owen «con sus líneas pueriles y simples, sus formas irresueltas, sus colores elementales» (1934b), se transforma bajo su mirada, se convierte en un mundo familiar y, sin embargo, lejano, inasible, lleno de añoranza. Los resultados prefiere llamarlos «versiones a ojo», no «traducciones» o «recreaciones», y ciertamente no «de oído», para así recalcar que el principio rector de su trabajo es siempre la imagen, la impresión visual del poema sobre la página, la evocación de esas formas y colores que configuran «el estío indiano» de Amherst tanto como «el amarillo amargo mar de Mazatlán» (I996: 7I). Owen no se guía por el oído, aunque mucho podría decirse de la sonoridad de sus versiones españolas, de su prosodia discreta y minuciosa, de sus rimas, a veces rotundas, a veces meramente insinuadas: traducir «a ojo» a Emily Dickinson le exige, confesadamente (I934b), la adopción de una «actitud de improvisación y descuido» que le permite eludir «el léxico solemne y la retórica convencional que [ella] rechazaba» y conseguir así un poema que tenga un efecto certero en el lector; un impacto enérgico, aquel «temblor inexplicable» que la propia Dickinson asociaba con la "poesía pura» y que Owen considera tan imprescindible que no duda en traducir, a manera de explicación o justificación, a partir de un pasaje hallado en sus cartas:

Si al leer un libro siento que todo el cuerpo se me hiela, en forma tal que ningún incendio podría calentármelo, yo sé bien que es poesía. Si siento al leerlo, en sensación solamente física, como si me arrancasen el cráneo, yo sé bien 
que es poesía. Son ésas las únicas maneras que tengo yo de saberlo. (1934b) ${ }^{13}$

Owen se propone «resucitar [a Dickinson] en otro siglo», conservar «tan pura su voz en la distancia» (I934b), y traducirla al español, a su español, a su propia experiencia de vida, es parte de una búsqueda también suya por encontrar «la medida exacta de su luz». En esta frase, me parece, quedan resumidos los propósitos de Owen al traducir a Emily Dickinson. La alusión, intencional o no, es a un poema de la propia Emily, «The Poets light but Lamps - / Themselves - go out» (J883), y forma parte de una larga elegía que Owen dice haber compuesto en su honor:

Toda la noche bailáramos un viento que pensaba

pongamos la lámpara bajo el almud sepamos la medida exacta de su luz que si en tanto a ninguno alumbra ya guiará a los pródigos de 2030 en su busca.

(1934b)

De dicha elegía sólo se conserva esta primera estrofa, y de los doscientos poemas de Dickinson que dijo haber traducido el poeta mexicano no sobreviven más que los ocho vestigios de El Tiempo colombiano. Conociendo a Owen, es probable que ninguna de esas dos cosas haya existido. Si se encuentran «soterradas en algún archivo personal» (Cajero 20I4: 37), sólo queda esperar que no sea hasta 2030 que algún pródigo las descubra. De cualquier modo, creo que es justo que se haga notar un hecho fundamental: las «Versiones a ojo» y los «Datos biográficos» de Emily Dickinson que publica

I3 «If I read a book and it makes my whole body so cold no fire can ever warm me, I know that is poetry. If I feel physically as if the top of my head were taken off, I know that is poetry. These are the only ways I know it.» (2012: 265)
Owen en Bogotá son textos mínimos, las unas en su frugalidad y los otros en su laconismo, pero en conjunto constituyen una de las pocas reflexiones teóricas y prácticas que existen sobre

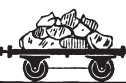
la traducción de poesía por parte de un escritor mexicano.

\section{CONCLUSIONES}

La labor de traducción que emprendieron los Contemporáneos se inscribe en el marco de un proyecto generacional que llevó siempre la encomienda de contribuir en la consolidación del patrimonio cultural de su nación y de América Latina. El grupo de Torres Bodet, Gorostiza, Villaurrutia, Novo, Cuesta y Owen - aunque a decir suyo no los reuniera más que la contigüidad de sus respectivas soledadesse dio asiduamente a la tarea de fomentar la actualización del pensamiento coetáneo a través de un universalismo crítico: además de su obra individual, el conjunto trabajó en la publicación de las principales revistas de vanguardia del país (Ulises, Contemporáneos), promovió el periodismo y la crítica culturales, colaboró en volúmenes característicos de la generación (Antología de la poesía mexicana moderna), fundó teatros para el montaje de obras dramáticas que «explorar[an] la subjetividad e intentar[an] formas poéticas y concepciones del espacio y tiempo más libres» (Rodríguez Chicharro I995: I26); escribió novelas experimentales, ensayó el flujo de conciencia, tradujo fecunda y abundantemente (a Pound y a Eliot, a Breton, Saint-John Perse y Cocteau) a fin de difundir e incorporar la poesía internacional más reciente. En suma, los Contemporáneos crearon una literatura universal mexicana, ajena a la miopía del localismo, y tradujeron precisamente para ayudar a franquear las fronteras nacionales. 
Con todo, y sin relegar ni un instante su función como mediador cultural en dicho programa, cabe suponer que las razones por las que Gilberto Owen tradujo la poesía de Emily Dickinson están relacionadas mucho más estrechamente con un viaje de exploración personal. Como Juan Ramón Jiménez, Owen aprende del ejemplo de Dickinson y a partir de él es que cultiva una manera de escribir poesía moderna, una poesía desvinculada de la opresión de los modelos, una poesía «plena» cuyo ritmo lo dicta ya sólo la claridad de la imagen, la justeza de la metáfora, la cadencia propia del pensamiento asociativo. La empresa en sí es pequeña como proyecto individual de traducción, pero, además de haber hecho figurar en el mapa de las letras hispánicas, desde entonces y para siempre, a una poeta «esquiva al mundo física y espiritualmente, [que] cerraba su mundo de poesía a todos los que la rodeaban» (1934b), Owen demostró, sin duda, que la labor traductora de un escritor puede ser un factor decisivo en la configuración y evolución de su poética.

Si las traducciones de los ocho poemas, realizadas declaradamente «a ojo», logran o no recrear «cuidadosa y trabajosamente [...] el temblor inexplicable, inaudible e invisible» (Owen I934b) de la obra de Emily Dickinson de acuerdo con cierto principio traductológico u otro - de correspondencia formal, de adecuación, de aceptabilidad, etcétera-, el asunto es, creo, objeto de una disquisición distinta. Sin embargo, incluso en caso de que se le encontrara a Owen algo digno de reproche en este ámbito, quizá convendría recordar, a propósito, que las nociones que comúnmente se tienen de «fidelidad» o equivalencia, y a menudo los prejuicios que condenan la «intromisión» intencional del traductor en sus originales, parten de doctrinas sumamente indeliberadas sobre la creatividad o, lo que es peor, sobre la traducción misma: como bien advierte
Michel Ballard, «la réécriture à l'aide d'une autre langue suppose des écarts ou des transformations qui font partie d'un acte de création» (I997: 86). El hecho de que Owen haya alcanzado un mimetismo con Emily Dickinson — no en el sentido estricto de mímesis, desde luego, sino en el sentido de haberse asimilado a ella, de haber asumido su voz - hizo que por un instante coincidieran, en una misma expresión poética, dos sensibilidades afines y sin embargo distintas. No siempre se dan encuentros tan afortunados.

RECIBIDO EN JUNIO DE 2018

ACEPTADO EN JUNIO DE 2018 VERSIÓN FINAL DE OCTUBRE DE 2018

\section{BIBLIOGRAFÍA}

\section{Fuentes consultadas}

Ballard, Michel (I997): «Créativité et traduction», en Target 9:I. pp. 85-Io0.

Beltrán Cabrera, Francisco Javier (20I4): «Emily Dickinson: un texto olvidado de Gilberto Owen», en La Colmena No. 63 (julio-septiembre). Toluca: Universidad Autónoma del Estado de México. pp. 37-4I.

Cajero Vázquez, Antonio (20I4): «Traducción y mediación: la obra dispersa de Gilberto Owen», en Literatura Mexicana Vol. xxv, No. 2. México, D. F.: UnAM. pp. 25-47.

Cohen, Sandro (s/f): «La epístola y el poema. La cita de Emily Dickinson y Gilberto Owen en Bogotá». http://www.sandrocohen.org/ensayo/ la_epistola_y_el_poe-ma.pdf. 23 de junio de 2013 .

DAuster, Frank (1963): Ensayos sobre poesía mexicana. Asedio a los «Contemporáneos». México, D. F.: Ediciones de Andrea (Colección Studium No. 4I).

Dickinson, Emily (1976): The Complete Poems of Emily Dickinson. Thomas H. Johnson, ed. Nueva York, Boston y Londres: Little, Brown and Company (Back Bay Books).

- (1993). The Collected Poems of Emily Dickinson. Martha Dickinson Bianchi, ed. Nueva York: Barnes and Noble. 
- (2012): Letters of Emily Dickinson. Mabel Loomis Todd, ed. Nueva York: Dover / Courier Corporation. González Ródenas, Soledad (2005): Juan Ramón Jiménez a través de su biblioteca. Lecturas y traducciones en lengua francesa e inglesa (I88I-1936). Sevilla: Universidad de Sevilla.

Henríquez Ureña, Pedro (I9I9): «La obra de Juan Ramón Jiménez». La Habana: Cuba Contemporánea, Año viI, Tomo xix, No. 75 (marzo).

JiménEZ, Juan Ramón (I9I7): Diario de un poeta recién casado. Madrid: Calleja.

- (I974): Páginas escojidas. Madrid: Gredos.

Leiter, Sharon (2007): Critical Companion to Emily Dickinson: A Literary Reference to Her Life and Work. Nueva York: Infobase Publishing (Facts on File).

Mitchell, Domhnall y Maria Stewart, eds. (2009): The International Reception of Emily Dickinson. Londres y Nueva York: Continuum.

Olea Franco, Rafael y Anthony Stanton, eds. (I994): Los Contemporáneos en el laberinto de la crítica. México, D. F.: Centro de Estudios Lingüísticos y Literarios, El Colegio de México.

Owen, Gilberto (I934b): «Emily Dickinson (Datos biográficos)». Bogotá: El Tiempo (Lecturas Dominicales) No. 536: 29 de abril. p. 8.

- (I996): Obras. Josefina Procopio, ed. $2^{\mathrm{a}}$ ed. aumentada. México, D. F.: Fondo de Cultura Económica (Letras Mexicanas).

Rodríguez Chicharro, César (I995): Estudios de literatura mexicana. México, D. F.: Facultad de Filosofía y Letras, UNAM.

Rosas, Alfredo (2009): «Emily Dickinson y Gilberto Owen: ese par de perversos», en La Colmena No. 63 (julio-septiembre). Toluca: Universidad Autónoma del Estado de México. pp. 28-36.

Segovia, Tomás (200I): Cuatro ensayos sobre Gilberto Owen. México, D. F.: Fondo de Cultura Económica (Letras Mexicanas).

Sheridan, Guillermo (I985): Los Contemporáneos ayer. México, D. F.: Fondo de Cultura Económica.

- (2008): Tres ensayos sobre Gilberto Owen. México, D. F.: unam.

Stanton, Anthony (I998): Inventores de tradición: ensayos sobre poesía mexicana moderna. México, D. F.: Fondo de Cultura Económica / El Colegio de México (Vida y Pensamiento de México).

- (2008): «Un poeta mexicano se apropia de las vanguardias europeas en Nueva York: "Autorretrato o del subway" de Gilberto Owen», en Revista Iberoamericana Vol. Lxxiv, No. 224 (julio-septiembre). Pittsburgh: Universidad de Pittsburgh. pp. $74 \mathrm{I}-750$.

Thomason, Elizabeth, ed. (200I): Poetry for Students (vol. I3). Farmington Hills: Gale Group.

Vendler, Helen (2006): Poets Thinking. Pope, Whitman, Dickinson, Yeats. Cambridge, Massachusetts y Londres: Harvard University Press.

\section{Algunas traducciones de Emily Dickinson}

Ardanaz, Margarita, trad. (20Io): Emily Dickinson. Poemas. Madrid: Cátedra.

Costa Picazo, Rolando, trad. (20II): Emily Dickinson. Oblicuidad de luz (95 poemas). Valencia: Universitat de Valéncia.

Champourcín, Ernestina de y Juan José DomenCHInA, trads. (I946): Emily Dickinson. Obra escogida. México: Centauro (Colección Poesía Mejor).

Leoni, Anna María, trad. (2005): Emily Dickinson. Los sótanos del alma. Mérida, Venezuela: El Otro, El Mismo.

Manent, Marià, trad. (1986): Emily Dickinson. Poemas. Madrid: Visor.

Mañeru Méndez, Ana y María-Milagros Rivera Garretas, trads. (2012): Emily Dickinson. Poemas I-60o. Fue - culpa - del paraíso. Madrid: Sabina.

- (2013): Emily Dickinson. Poemas 60I-I200. Soldar un abismo con aire. Madrid: Sabina.

- (2015): Emily Dickinson. Poemas I2OI-I786. Nuestro Puerto un secreto. Madrid: Sabina.

Ocampo, Silvina, trad. (2006): Emily Dickinson. Poemas. Barcelona: Tusquets.

Oliván, Lorenzo, trad. (200I): Emily Dickinson. La soledad sonora. Madrid: Pretextos.

Owen, Gilberto, trad. (I934a): «Poemas de Emily Dickinson. Versiones a ojo de Gilberto Owen». Bogotá: El Tiempo (Lecturas Dominicales) No. 536: 29 de abril. pp. 6-7.

Pasini, Delia, trad. (20I4): Antología poética de Emily Dickinson. Buenos Aires: Losada.

Rey, José Luis, trad. (2013): Emily Dickinson. Poesía completa. Madrid: Visor.

Rodríguez Monroy, Amalia, trad. (200I): Emily Dickinson. Antología bilingüe. Madrid: Alianza.

Villar Raso, Manuel, trad. (200I): Emily Dickinson. Crónica de plata: poemas escogidos. Madrid: Hiperión.

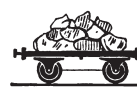

